\title{
RECONOCIMIENTO DE LA CONDICIÓN DE REFUGIADO EN MÉXICO: PERSONAS LGBTI Y DISCRIMINACIÓN EN GUATEMALA
}

\author{
Rafael Andree Salgado Mejía*
}

DOI: https://doi.org/10.5377/Ird.v41i1.10488

\section{RESUMEN:}

El presente trabajo destaca los elementos más relevantes del estudio y análisis de realizados en la resolución de la Novena Sala Regional Metropolitana del Tribunal Federal de Justicia Administrativa de los Estados Unidos Mexicanos, en la que reconoce la condición de refugiado a un solicitante de nacionalidad guatemalteca que se identifica como gay en un contexto de violencia y discriminación por orientación sexual e identidad de género, elaborando una definición de refugiado incluyendo un componente de género de conformidad de la normativa de origen tanto nacional -México- como internacional en materia de asilo y analiza los hechos y actos controvertidos del caso desde una perspectiva de derechos humanos y con base a principios relacionados al Derecho Internacional de los Refugiados, de los que se destacan los Principios 18 y 23 de Yogyakarta.

\section{PALABRAS CLAVE:}

Refugiados; Derechos Humanos; Principios de Yogyakarta; Discriminación; Identidad de Género; Orientación Sexual; LGBTI; Guatemala; México.

Fecha de recepción: 20 de agosto de 2020 Fecha de aprobación: 27 de octubre de 2020

\footnotetext{
* Ex practicante de la Clínica Jurídica para Refugiados Alaíde Foppa (CJR) de la Universidad Iberoamericana Ciudad de México (IBERO), Maestro en Derechos Humanos por la Universidad Iberoamericana Ciudad de México (IBERO) y Abogado por la Universidad Nacional Autónoma de Honduras (UNAH).rasmsr@hotmail.com. Supervisión y revisión a cargo de Lorena Cano Padilla, Elba Coria Márquez, Luis Xavier Carrancá Álvarez, clinicaderefugiados@ibero.mx
} 


\title{
RECOGNITION OF REFUGEE STATUS IN MEXICO: LGBTI PERSONS AND DISCRIMINATION IN GUATEMALA
}

\author{
Rafael Andree Salgado Mejía* \\ DOI: https://doi.org/10.5377/Ird.v41i1.10488
}

\begin{abstract}
:
This paper highlights the most relevant elements of the study and analysis of the decision carried out in the resolution of the Ninth Metropolitan Regional Chamber of the Federal Administrative Court of the United Mexican States, in which it recognizes the refugee status to an applicant of Guatemalan nationality who identifies as gay in a context of violence and discrimination based on sexual orientation and gender identity. In this case, the ninth regional chamber has developed a definition of refugee that includes a gender component in accordance with national (Mexico) and international norms on asylum, and has analyzed the facts and controversial acts in the case from a human rights perspective and on the basis of principles related to international law Refugees, highlighting Principles 18 and 23 of Yogyakarta.
\end{abstract}

\section{KEY WORDS:}

Refugees; Human Rights; Yogyakarta`s Principle; Discrimination; Gender Identity; Sexual Orientation; LGBTI; Guatemala; Mexico.

Date received: August 20, 2020 Approval date: October 27, 2020

\footnotetext{
** Former practitioner at the Alaíde Foppa Legal Clinic for Refugees (CJR) of the Ibero-American University Mexico City (IBERO), Master in Human Rights from the Ibero-American University of Mexico City (IBERO) and Lawyer from the National Autonomous University of Honduras (UNAH).rasmsr@hotmail.com. Supervision and review by Lorena Cano Padilla, Elba Coria Márquez, Luis Xavier Carrancá Álvarez, clinicaderefugiados@,ibero.mx
} 


\section{INTRODUCCIÓN}

En este artículo se analiza la sentencia definitiva de fecha 13 marzo de 2018 dictada dentro del expediente 16586/17-17-09-8, por la Novena Sala Regional Metropolitana del Tribunal Federal de Justicia Administrativa ${ }^{1}$. El caso fue litigado por la Clínica Jurídica para Refugiados Alaíde Foppa ${ }^{2}$ (en adelante CJR), misma que en el marco de sus actividades, representó a CNL, originario de Guatemala, quien se identifica como gay, y en ese sentido al pertenecer a un grupo social-LGBTI ${ }^{3}$-, en un contexto de violencia generalizada en contra del supra grupo, solicitó ante la autoridad competente mexicana el reconocimiento de la condición de refugiado al expresar un temor fundado de persecución en su país de origen por motivo de su orientación sexual. La Delegación en Veracruz de la Coordinación General de la Comisión

1 La Novena Sala Regional Metropolitana del Tribunal Federal de Justicia Administrativa estaba integrada por las Magistradas María Eugenia Rodríguez Pavón, titular de la primera ponencia; María Bárbara Templos Vázquez, titular de la Segunda Ponencia e instructora en el juicio, y María del Carmen Tozcano Sánchez, Titular de la Tercera Ponencia.

2 Espacio teórico-práctico que ofrece a los estudiantes de la Universidad Iberoamericana, Ciudad de México, la oportunidad de ampliar y llevar a la práctica sus conocimientos del derecho al tiempo en que brindan servicios legales especializados y gratuitos a favor de personas con necesidades de protección nacional e internacional que, haciendo uso del litigio estratégico se busca a través de resoluciones y sentencias un efecto transformador en la sociedad.

3 Como bien señaló la Corte Interamericana de Derechos Humanos en la opinión consultiva OC-24/17 ( $[$ Corte IDH, 2017) y retomando esa idea para el presente artículo, se hará uso de esta sigla tomando en cuenta que la terminología relacionada con estos grupos humanos no es fija y evoluciona rápidamente, y que existen otras diversas formulaciones que incluyen a personas Asexuales, Queers, Trasvestis, Transexuales, Intersex, entre otras y de igual manera, así como ha sido la práctica de la Asamblea General de la OEA y como lo hizo la propia Corte IDH en esa opinión, se utilizará esta sigla de forma indistinta sin que ello suponga desconocer otras manifestaciones de expresión de género, identidad de género u orientación sexual.
Mexicana de ayuda a Refugiados (en adelante COMAR) dependiente de la Secretaria de Gobernación, resolvió no reconocerle la condición de refugiado mediante resolución de fecha 26 de abril de 2017. Inconforme con el fallo se combatió la negativa a través del juicio contencioso administrativo ante el Tribunal Federal de Justicia Administrativa. En esa instancia la Novena Sala Regional Metropolitana construye una definición de refugiado incluyendo un componente de género de conformidad de la normativa mexicana e internacional sobre refugiados y analizó el caso desde una perspectiva de derechos humanos, con base a los principios relacionados al Derecho Internacional de los Refugiados, de los que se destacan los Principios 18 y 23 de Yogyakarta y en consecuencia de lo anterior, reconoce a CNL la condición de refugiado. El objetivo de este trabajo es resaltar como una acción positiva la implementación de la perspectiva de género bajo el enfoque de los derechos humanos en aras de garantizar mayor rango de protección para las personas solicitantes del reconocimiento de la condición de refugiado. Esta resolución es un precedente positivo porque a diferencia de otros casos de acceso al asilo ante instancias de impartición de justicia, en ésta el Tribunal se pronuncia sobre el fondo del asunto y analiza desde una perspectiva de derechos humanos los hechos y actos controvertidos y visibilizando la necesidad de la utilización de los derechos humanos y la perspectiva de género de las personas solicitantes de protección internacional. Asimismo, la sala sostuvo una posición progresista y conocedora de estándares y principios internacionales de derechos humanos, por ejemplo, al aplicar e interpretar los principios de Yogyakarta y la 
definición de refugiado de conformidad de la normativa de origen tanto nacional como internacional en materia de asilo.

\section{METODOLOGÍA}

Se utiliza la metodología de Investigación Jurídica en su variante de metodología práctica. Como explica Sánchez Zorrilla (2011), esta metodología consiste en conocer la forma en que resuelven los jueces una controversia jurídica, estudia los razonamientos, criterios de argumentación, la forma en que el juzgador es capaz de interpretar las normas en el caso objeto de estudio resuelto por el mismo, de tal manera que "se pueda construir de forma ordenada y lógica, un método que servirá para que otros jueces o doctrinarios hagan lo mismo" (Zorrilla,2011, pp. 332333). Asimismo, La postura epistemológica o bien, la teoría del conocimiento en la que se cimentará el presente artículo es el sincretismo metodológico, la cual concilia tres posturas: el formalismo jurídico (normas); el Realismo Jurídico (hechos, es decir, jurisprudencia) y; el iusnaturalismo (principios). En atención a lo anterior, este artículo se desarrolla de la siguiente manera: en primer lugar, se hace alusión a los hechos del caso y el contexto en el que ocurrieron los mismos los cuales generaron actos equiparables a la persecución pues, se trata de un caso donde la discriminación configura una forma de persecución. También, se mencionará el contexto de discriminación en Centroamérica en contra de personas que pertenecen al grupo de LGBTI, para luego definir el concepto de refugiado. El análisis reproduce el contenido de la sentencia en análogo orden, desarrollando los principios que utilizó la sala para determinar si se cumplían los elementos para reconocer el estatuto de refugiado, dedicando posteriormente un apartado especial sobre el grupo LGBTI, Para finalizar, se desarrollará la parte resolutiva de la sentencia objeto de estudio.

\section{HECHOS DEL CASO Y CONTEXTO DE DISCRIMINACIÓN EN CENTROAMÉRICA}

CNL se identifica como gay, en un contexto de violencia y discriminación por orientación sexual y la identidad de género, decide salir de su país y solicitar protección en México. Los hechos que dan cuenta de la violencia y discriminación que vive son sustentados por el recurrente en su solicitud ante la COMAR. La Sala Metropolitana al analizar y valorar si en efecto la persona no reunía los elementos para ser reconocida como refugiada retoma los hechos narrados por el solicitante y transcritos en la propia resolución de la COMAR de fecha 14 de diciembre de 2016 y los sintetiza de la siguiente manera:

Que se reconoce como gay pero que en su aldea no lo aceptan; que le dicen que a los gays hay que matarlos y en la calle lo insultan; Le dicen maldito maricón, ustedes (los gays) se van a ir al infierno, no los queremos aquí; Que 3 semanas atrás mataron a un chico por ser gay; Que en Guatemala vivía en un circo, salía de payaso y andaba por varios lugares de su país de origen; que desde los 11 años empezó a trabajar en el circo, porque su mamá lo echó de la casa al encontrarle un mensaje de un chico, que era su novio; Que a los 8 años se dio cuenta que tenía preferencia (sic) por los chicos; Que a los 12 años su tía OLB lo sacó del circo; Que con su tía estuvo hasta la edad de los 14 años, pues estando con ella lo mandaba a robar y a vender droga; que su tía le pegaba cuando lo mandaba a robar y no le llevaba 
lo que le pedía; Que cuando tenía 5 años su tío $\mathrm{H}$ abusó de él, específicamente un 24 de diciembre; Que ese hecho se lo contó a su madre, pero no le creyó; Que cuando tenía 7 años, su tía M lo agarró del pescuezo queriéndolo ahorcar y le dijo "este va ser gay entonces hay que matarlo"; Que cuando iba a la escuela con otro compañero en el progreso en una aldea que se lama "pozas de Agua", su compañero también era gay y decían "estos malditos maricas no los queremos aquí", incluso nos llegaron a pegar un día; Que los compañeros de la secundaria le dijeron que tenía dos días de salir de la aldea si no lo matarían; Que decidió salir de su país por su mamá que lo mandaba buscar y por las personas que lo rechazaban; Que su mamá lo mandó buscar en 20 ocasiones, después de que se salió de con ella; Que a los 17 años fue a la policía y les explicó todo, pero le dijeron que era menor de edad y que tenía que ir con su mamá y con "alguien de más edad", sin que le tomaran su denuncia; Que no puede vivir en otra parte de Guatemala, porque lo buscan para matarlo; Que su temor es que lo maten si regresa. (16586/17-1709-8, 2018, pp.43-45)

A juicio de la Sala los hechos descritos fueron suficientes para demostrar que la persona era refugiada. Ello tomando como punto de partida que, como lo asevera el Alto Comisionado de las Naciones Unidas para los Refugiados [ACNUR, 2011a) y lo refrenda la Corte Interamericana de Derechos Humanos (Corte IDH,2013) que, de conformidad con la Convención de 1951 una persona es un refugiado tan pronto como reúne los requisitos enunciados en la definición, lo que necesariamente pasa antes que se determine formalmente su condición de refugiado. En consecuencia, no adquiere la condición de refugiado en virtud del reconocimiento, sino que se le reconoce tal condición por el hecho de ser refugiado, es decir, dicho reconocimiento no tiene carácter constitutivo, sino declarativo.
Es un hecho indiscutible que las personas LGBTI en Guatemala, Honduras y El Salvador, viven en un contexto de discriminación por parte de la sociedad. el Alto Comisionado de las Naciones Unidas para los Refugiados (ACNUR, s.f.) señala que las personas LGBTI del Norte de Centroamérica de forma desproporcionada y a temprana edad son víctimas de discriminación grave y de distintas formas de violencia sexual, física y psicológica tanto en el entorno social como familiar. También destaca que el $88 \%$ de las personas solicitantes de asilo y refugiadas LGBTI entrevistadas por ACNUR reportaron haber sufrido violencia sexual y de género en sus países de origen y que las pandillas o grupos criminales en estos países dirigen actos de violencia a personas LGBTI basadas en su identidad de género u orientación sexual real o percibida, sometiéndolos a la violencia física y sexual, así como a la extorsión y al trabajo forzado. También organizaciones no gubernamentales internacionales se han pronunciado al respecto. Erika Guevara Rosas, directora para las Américas de Amnistía Internacional afirmó que en "Centroamérica hay personas que sufren una terrible discriminación por su identidad de género, y no tienen absolutamente ningún sitio al que huir en busca de seguridad." (Amnistía Internacional, 2017)

\section{DEFINICIÓN DE REFUGIADO \\ DE ACUERDO A LA NORMATIVA DE ORIGEN NACIONAL E INTERNACIONAL}

Dadas las características del caso objeto de estudio, laNovenaSala Regional Metropolitana del TFJA, consideró necesario precisar el 
marco teórico del mismo, definiendo la calidad de refugiado y en consecuencia los elementos que deben materializarse para reconocer el estatuto de refugiado. Para ello, hizo uso de los siguientes instrumentos de origen Internacional y nacional: (1) la Convención sobre el Estatuto de los Refugiados de 1951 y el Protocolo sobre el Estatuto de los Refugiados de 1967; (2) la Declaración de Cartagena sobre Refugiados de 1984; (3) Ley sobre Refugiados, Protección Complementaria y Asilo Político y, el Reglamento de la Ley sobre Refugiados y Protección Complementaria.

1. Convención sobre el Estatuto de los Refugiados de 1951 y el Protocolo sobre el Estatuto de los Refugiados de 1967: La Convención de 1951 fue adoptada en Ginebra, Suiza, el 28 de julio de 1951 por la Conferencia de Plenipotenciarios sobre el Estatuto de los Refugiados y de los Apátridas y en virtud de su artículo 43 entró en vigor el 22 de abril de 1954. El Protocolo sobre el Estatuto de los Refugiados fue firmado en Nueva York el 31 de enero de 1967 y entró en vigor el 4 de octubre de 1967 de conformidad con el artículo VIII. El Estado mexicano se adhirió a ambos instrumentos el 7 de junio de 2000 (ACNUR,2011b). A Convención de 1951 en el artículo 1 literal A, numeral 2) define el término refugiado así:

Artículo 1. Definición del término "refugiado" A. A los efectos de la presente Convención, el término "refugiado" se aplicará a toda persona:

[... 2) Que, como resultado de acontecimientos ocurridos antes del $1 .^{\circ}$ de enero de 1951 y debido a fundados temores de ser perseguida por motivos de raza, religión, nacionalidad, pertenencia a determinado grupo social u opiniones políticas, se encuentre fuera del país de su nacionalidad y no pueda o, la causa de dichos temores, no quiera acogerse a la protección de tal país; o que, careciendo de nacionalidad y hallándose, a consecuencia de tales acontecimientos, fuera del país donde antes tuviera su residencia habitual, no pueda o, a causa de dichos temores, no quiera regresar a él. [...] Énfasis añadido

Por otro extremo, en virtud del Protocolo sobre el Estatuto de los Refugiados, en su artículo I, párrafo 2, se eliminan las palabras "como resultado de acontecimientos ocurridos antes del $1 .^{\circ}$ de enero de 1951" y las palabras "... a consecuencia de tales acontecimientos", que figuran en el párrafo 2 de la sección A del artículo 1. En atención al artículo 1 de la Convención y el artículo I, párrafo 2 del Protocolo en relación a la definición de refugiado, la Sala concluyó que se define como refugiado a aquella persona que debido a:

[F]undados temores de ser perseguida por motivos de raza, religión, nacionalidad, pertenencia a determinado grupo social u opiniones políticas, se encuentre fuera del país de su nacionalidad y no pueda o, a causa de dichos temores, no quiera acogerse a la protección de tal país; o que, careciendo de nacionalidad y hallándose, a consecuencia de tales acontecimientos, fuera del país donde antes tuviera su residencia habitual, no pueda $\mathrm{o}$, a causa de dichos temores, no quiera regresar a él. (16586/17-17-09-8, 2018, pp.7-8)

2. Declaración de Cartagena sobre Refugiados: Fueadoptadoporel "Coloquio Sobre la Protección Internacional de los Refugiados en América Central, México y Panamá: Problemas Jurídicos y Humanitarios", celebrado en Cartagena, Colombia, del 19 al 22 de noviembre de 
1984. En su conclusión Tercera, reitera que:

[...] en vista de la experiencia recogida con motivo de la afluencia masiva de refugiados en el área centroamericana, se hace necesario encarar la extensión del concepto de refugiado, teniendo en cuenta, en lo pertinente, y dentro de las características de la situación existente en la región, el precedente de la Convención de la OUA (artículo 1, párrafo 2) y la doctrina utilizada en los informes de la Comisión Interamericana de Derechos Humanos. De este modo, la definición o concepto de refugiado recomendable para su utilización en la región es aquella que además de contener los elementos de la Convención de 1951 y el Protocolo de 1967, considere también como refugiados a las personas que han huido de sus países porque su vida, seguridad o libertad han sido amenazadas por la violencia generalizada, la agresión extranjera, los conflictos internos, la violación masiva de los derechos humanos u otras circunstancias que hayan perturbado gravemente el orden público. (Lo resaltado es nuestro)

Este instrumento internacional es de los denominados "declarativos", es decir, en primera instancia no es de carácter vinculante. Empero, la protección que brinda la Declaración es más amplia que la Convención del 51, porque la definición de refugiado de este instrumento declarativo incorpora los 5 motivos de la Convención de 1951 que son de raza (I), religión (II), nacionalidad (III), pertenencia a determinado grupo social (IV) u opiniones políticas (V) y, además incluye 5 elementos o motivos de contexto para Latinoamérica: violencia generalizada (I), la agresión extranjera (II), los conflictos internos (III), la violación masiva de los derechos humanos (IV) u otras circunstancias que hayan perturbado gravemente el orden público (V).
Considerando los elementos de la Declaración de Cartagena, la Sala Metropolitana (2018) concluyó que una persona es refugiada "en el momento en que se establece el nexo causal entre el temor fundado de persecución y uno de los cinco motivos previstos en la convención o alguno de los motivos agregados en la Declaración de Cartagena" (p.10). Es decir, a pesar de que la Declaración no es en principio vinculante, la Sala reconoce plenamente que los motivos de la definición de Cartagena para la condición de refugiado en México al ser incorporados en la legislación nacional, obliga al reconocimiento como refugiadas a las personas que huyen de su país conforme a los elementos de la declaración. Se destaca que en esa misma línea las Magistradas de la Novena Sala, al analizar la declaración de Cartagena, se refirieron de los artículos $1^{4}$ y $2^{5}$ de la Declaración Universal de Derechos Humanos y en ese sentido interpretaron que "toda persona LGTBI, tienen derecho a gozar de la protección prevista en el derecho internacional de los derechos humanos basado en la igualdad y la no discriminación" (16586/17-17-09-8, 2018, pp.10-11). De igual manera "dado que los derechos fundamentales, así como el principio de no discriminación, son aspectos fundamentales de la Convención de 1951 y el Derecho Internacional de los Refugiados, la definición de refugiado debe interpretarse y aplicarse con la debida atención a ellos, incluyendo la prohibición de no discriminación relacionada con la orientación sexual e identidad de género" (16586/17-17-09-8, 2018, p.11).

4 Art. 1. Todos los seres humanos nacen libres e iguales en dignidad y derechos [...]

5 Art 2. Toda persona tiene todos los derechos y libertades proclamados en esta Declaración [...] 
Agregándose al supra análisis, también hay que hacernotarqueel derecho alaigualdady ala no discriminación, se encuentran consagrados en la Constitución Política de los Estados Unidos Mexicanos, como en instrumentos internacionales de carácter normativo ${ }^{6}$ del sistema regional y universal de los derechos humanos. El Estado Mexicano en virtud al artículo 1.1 de la Convención Americana sobre Derechos Humanos (En adelante $\mathrm{CADH}$ ) se encuentra obligado a "respetar los derechos y libertades" consagrados en la referida convención y "a garantizar su libre y pleno ejercicio a toda persona que esté sujeta a su jurisdicción, sin discriminación alguna." Asimismo, en función al artículo 24 de la CADH se obliga a respetar y garantizar todos aquellos derechos reconocidos de manera formal, es decir, todos aquellos consagrados en las leyes aprobadas en la forma prevista en la constitución, así como de los tratados internacionales -distintos a la CADH- de los que el Estado mexicano sea parte (Corte IDH, 2005).

\section{Ley sobre Refugiados, Protección} Complementaria y Asilo Político Reglamento de la Ley sobre Refugiados y Protección Complementaria: Tal como lo señala la Sala Metropolitana del TFJA, en la legislación mexicana se reconoce la condición de refugiado, tomando en consideración los elemento para tal efecto estipulados en la Convención de 1951 y

6 Santiago Corcuera Cabezut señala que los tratados internacionales sobre derechos humanos son de índole normativa, es decir, que son de aquellos que no imponen obligaciones reciprocas a los Estados, sino que, en oposición a los de carácter sinalagmáticos, obligan a los Estados para lograr un beneficio a la Humanidad. (Corcuera Cabezut, 2016, p. 104) el Protocolo de 1967; la Declaración de Cartagena ${ }^{8}$ - lo que hace de esta definición vinculante para el Estado Mexicano- y, "recoge en conjunto las definiciones de tales instrumentos, aplicándolos respecto de aquellas personas que ya se hubieren encontrado en territorio nacional al momento de surgir las hipótesis para el reconocimiento del carácter de refugiado ("sur place")""; no menos importante resulta enfatizar que, la Ley sobre derecho de asilo mexicana, además de adoptar la definición convencional de persona refugiada, y hacer vinculante la definición ampliada para Latinoamérica, además agrega un sexto motivo en su fracción I, para incluir el género.

\section{Elementos de la definición de refugiado:}

7 [...] La condición de refugiado se reconocerá a todo extranjero que se encuentre en territorio nacional, bajo alguno de los siguientes supuestos: I. Que debido a fundados temores de ser perseguido por motivos de raza, religión, nacionalidad, género, pertenencia a determinado grupo social u opiniones políticas, se encuentre fuera del país de su nacionalidad y no pueda o, a causa de dichos temores, no quiera acogerse a la protección de tal país; o que, careciendo de nacionalidad y hallándose, a consecuencia de tales acontecimientos, fuera del país donde antes tuviera residencia habitual, no pueda o, a causa de dichos temores, no quiera regresar a él. (Ley sobre Refugiados, Protección Complementaria y Asilo Político [LRPAP], 2011, artículo 13, romano I).

8 Que ha huido de su país de origen, porque su vida, seguridad o libertad han sido amenazadas por violencia generalizada, agresión extranjera, conflictos internos, violación masiva de los derechos humanos u otras circunstancias que hayan perturbado gravemente el orden público. (LRPAP, 2011, artículo 13, romano II).

9 Que debido a circunstancias que hayan surgido en su país de origen o como resultado de actividades realizadas, durante su estancia en territorio nacional, tenga fundados temores de ser perseguido por motivos de raza, religión, nacionalidad, género, pertenencia a determinado grupo social u opiniones políticas, o su vida, seguridad o libertad pudieran ser amenazadas por violencia generalizada, agresión extranjera, conflictos internos, violación masiva de los derechos humanos u otras circunstancias que hayan perturbado gravemente el orden público. (LRPAP, 2011, artículo 13, romano III). 
Los elementos que son indispensables para que el Estado mexicano reconozca la condición de refugiado de acuerdo a la normativa nacional e internacional son: a) Encontrarse fuera de su país de origen o residencia habitual; b) Temor fundado; c) Persecución, y; d) Alguno de los motivos de la Convención de 1951, de la Declaración de Cartagena o la ley sobre refugiados, protección complementaria y asilo político.

\section{a. Encontrarse fuera de su país de origen} o residencia habitual: El Manual y Directrices sobre Procedimientos y Criterios para Determinar la Condición de Refugiado de acuerdo con la Convención de 1951 del ACNUR (en adelante MDPC) señala que, es un requisito para obtener el estatuto de refugiado es que el solicitante "se encuentre fuera del país de su nacionalidad. No hay excepciones a esta regla. La protección internacional no puede entrar en juego mientras la persona se encuentre bajo la jurisdicción territorial de su país de origen" (ACNUR, 2011a, párr. 88). Asimismo, agrega que, "cuando un solicitante alega temores de ser perseguido en el país de su nacionalidad, se debe determinar si en realidad posee la nacionalidad de ese país" (ACNUR, 2011ª párr.89).

b. Temor fundado: En términos generales el MDPC en los párrafos 37 al 50 se desarrolla en qué consisten los "fundados temores de ser perseguida" y a la luz de lo contemplado en ese manual, en específico en los párrafos 37 al 47, se interpretó el temor fundado de la siguiente manera:

[...] es claro que el "temor" se define como un estado de ánimo, mismo que al ser de carácter subjetivo, necesariamente requiere basarse en una situación objetiva para poder determinar la condición de refugiado de una persona; por la que la expresión "fundados temores" contiene un elemento subjetivo (temor) y un elemento objetivo (fundados), que deben tomarse en consideración de manera conjunta. (16586/17-17-09-8, 2018, p.25) [...] para determinar el elemento subjetivo, es indispensable la apreciación de la personalidad del solicitante, evaluándose el grado de credibilidad cuando el caso no resulte suficientemente claro a la luz de los hechos de que se tenga constancia, y será necesario tener en cuenta los antecedentes personales y familiares del solicitante, su pertenencia a un determinado grupo racial, religioso, nacional, social o político, la forma en que interpreta su situación y sus experiencias personales; es decir aquellos elementos que puedan servir para indicar que el motivo predominante de su solicitud es el temor. Por otro lado, en cuanto al elemento objetivo, se destaca que resulta necesario evaluar las declaraciones del solicitante, y si bien no se exige de las autoridades competentes que emitan un juicio sobre la situación en el país de origen, las declaraciones no pueden ser consideradas en abstracto y deben examinarse en el contexto de la situación pertinente, convirtiéndose así en un elemento importante para evaluar el grado de credibilidad de esa persona. Asimismo, los temores del solicitante pueden considerarse fundados si puede demostrar, en medida razonable, que la permanencia en su país de origen se le ha hecho intolerable por las razones indicadas en la definición o que, por esas mismas razones, le resultarían intolerables en caso que regresara a él. (16586/17-17-09-8, 2018, p.26) [...] aquello a tomar en consideración no tiene que estar 
basado necesariamente en la experiencia personal del solicitante, siendo que lo ocurrido, por ejemplo, a amigos o parientes puede ser indicio suficiente de que sus temores de convertirse también, en víctima de persecución son fundados. (16586/17-1709-8, 2018, p.27)

En el ordenamiento jurídico mexicano, define fundados temores en el artículo 2 fracción III de la Ley Sobre Refugiados, Protección Complementaria y Asilo Político, como "los actos y hechos que den o hayan dado lugar a una persecución" que "ponen o podrían poner en riesgo la vida, la libertad o la seguridad de una persona."

c. Persecución: En virtud del artículo 33 de la Convención de 1951 y la conclusión tercera de la Declaración de Cartagena podemos señalar que toda amenaza contra la vida, la libertad o la seguridad de una persona por motivos de raza, religión, nacionalidad, pertenencia a determinado grupo social $u$ opiniones políticas es siempre persecución. También constituirían persecución alguno de los motivos de contexto establecidos en la Declaración de Cartagena como ser: violencia generalizada, la agresión extranjera, los conflictos internos, la violación masiva de los derechos humanos u otras circunstancias que hayan perturbado gravemente el orden público. En referencia a este elemento la Sala Metropolitana para establecer que en el presente caso existe persecución se apoya en lo establecido en los párrafos 51, 52 y 53 del MDPC llegó a la misma conclusión agregando que "la propia legislación en el artículo 6 del Reglamento de la Ley sobre Refugiados y Protección Complementaria, reconoce precisamente como supuesto de persecución, los actos de violencia sexual" (16586/17-17-09-8, 2018, p.29) y en relación a lo anterior, "el término amenaza se entiende como "intimidar a alguien con el anuncio de la provocación de un mal grave para él o su familia" (16586/17-1709-8, 2018, p. 30).

Asimismo, cabe precisar que "una vez que se han decretado represalias contra un individuo o una familia, la gravedad de la amenaza no disminuye con el tiempo" (ACNUR, 2010, párr. 6) y que para la configuración de la persecución basta con la amenaza a los derechos a la vida y a la libertad, sin que se establezca que está deba cumplirse y mucho menos que implique su materialización en un daño físico (16586/17-17-09-8, 2018, p.30). Además de hacer alusión a lo que la Sala Metropolitana interpretó como "persecución", es importante identificar quienes son los sujetos activos de la misma, para ello si nos remitimos a lo señalado en el MDPC, la persecución puede ser por parte de agentes estatales o no estatales definidos. El MDPC también señala que el "comportamiento vejatorio o gravemente discriminatorio observado por ciertos sectores de la población local puede equipararse a la persecución si es deliberadamente tolerado por las autoridades o si éstas se niegan a proporcionar una protección eficaz o son incapaces de hacerlo" (ACNUR, 2011a, párr. 65). En el presente caso, la Sala tomando en consideración el párrafo $65 \mathrm{del}$ MDPC estableció que, como sujeto activo de la persecución se distinguen: a) Agente 
Estatal: Resultado de la actuación de las autoridades de un país, y b) Agentes de sectores de la población: Que no respetan las normas establecidas por las leyes de su país (16586/17-17-09-8, 2018, p.36).

En México, el artículo 7 del Reglamento de la Ley Sobre Refugiados y Protección Complementaria, señala quienes son los sujetos activos de la persecución pudiendo ser estos, entre otros actores, por representantes o miembros del Estado o personas que actúen de manera legítima o ilegítima en su nombre; asociaciones $u$ organizaciones que controlen el territorio de un Estado o una parte considerable del mismo; agentes no estatales, cuando sean tolerados por las autoridades o bien, si éstas se niegan o son incapaces de proporcionar protección eficaz en contra de las acciones de éstos, y; sectores de la población que no respetan las normas establecidas por los ordenamientos legales.

\section{d. Alguno de los motivos de la Convención de 1951, de la Declaración de Cartagena} o la ley sobre refugiados, protección complementaria y asilo político: Como se ha desarrollado y consta en la sentencia dictada por la Novena Sala del TFJA, debe existir un nexo causal entre el temor fundado de persecución y al menos uno de los motivos establecidos en la definición de refugiado de la Convención de 1951 o en la Declaración de Cartagena de 1984. En el presente caso, la Sala de forma acertada estableció que la solicitud del reconocimiento de la condición de refugiado tenía como motivación "un componente de género de la condición de refugiado y/o pertenencia a un determinado grupo social" (16586/17-17-09-8, 2018, p.33). Bajo esa tesitura, la Novena Sala procedió a remitirse a las Directrices sobre la protección internacional: "Pertenencia a un determinado grupo social" en el contexto del Artículo 1 A (2) de la Convención de 1951 sobre el Estatuto de los Refugiados y/o su Protocolo de 1967, en específico, los párrafos 1, 11, 15, 16, 17 y 18 de los cuales para el análisis al caso en concreto tomó los siguientes elementos:

[...] determinado grupo social es "un grupo de personas que comparten una característica común distinta al hecho de ser perseguidas o que son percibidas a manudo como grupo por la sociedad" y dicha característica, entre otros supuestos, será innata e inmutable, o fundamental de la identidad, la conciencia o el ejercicio de los derechos humanos [...] para considerarse como grupo social no se requiere cohesión; tampoco que todos los miembros de un grupo deben estar en riesgo de ser perseguidos; el tamaño del supuesto grupo social no es un criterio importante en la determinación de la existencia de un grupo social, en particular dentro de los fines del articulo 1 A (2); además, la simple pertenencia a un determinado grupo social no será suficiente para justificar una solicitud de la condición de refugiado. Sin embargo, pueden existir circunstancias especiales donde la simple pertenencia puede ser un fundamento para sentir temor de persecución. (16586/17-17-09-8, 2018, pp.39-40)

De igual manera, como se dijo en líneas anteriores, en la legislación mexicana se incluye un sexto motivo además de los establecidos en la Convención de 1951 que es: género. Con respecto a este motivo, el TFJA señaló en su sentencia que, "las solicitudes de asilo por motivos 
de orientación sexual y/o identidad de género a menudo emanan de miembros de subgrupos específicos" es decir, lesbianas, gays, bisexuales, transgéneros, travestis, transexuales, intersexuales, queer, entre otros. Al respecto, es importante resaltar algunos elementos que fueron considerados por el órgano colegiado en la sentencia:

[...]Las experiencias de los miembros de estos diversos grupos a menudo serán distintas unas de las otras, y entre sus miembros. Es, por lo tanto, esencial comprender tanto el contexto de cada solicitud de la condición de refugiado, así como los relatos individuales que no son fáciles de aplicar en experiencias comunes. [...] La sexualidad o las prácticas sexuales de un solicitante pueden ser relevantes en la solicitud de asilo cuando éste ha sido víctima de acciones persecutorias (incluyendo la discriminación) por razones de su sexualidad o prácticas sexuales. En muchos casos el solicitante se niega a observar roles y las expectativas sociales o culturales atribuidas a los miembros de su sexo. [...] es importante destacar que no todos los solicitantes se auto identifican con la terminología LGBTI..." [...] o puede que no conozcan estos términos. Puede incluso que algunos sólo se refieran a los términos (despectivos) utilizados por el perseguidor. Por ello, Como lo ha sostenido el Alto Comisionado de las Naciones Unidas para los refugiados, un análisis adecuado de si un solicitante LGBTI es un refugiado bajo la Convención de 1951 tiene que partir de la premisa de que los solicitantes tienen derecho a vivir en la sociedad como lo que son y no necesitan ocultarlo. (16586/17-1709-8, 2018, pp.18-19)

Es imprescindible definir sexo, género, identidad de género y orientación sexual. La diferencia entre sexo y género radica en que el primero se refiere a características biológicas, y el segundo a un conjunto de características de roles de expectativas sociales. Respecto a la identidad de género y orientación sexual los principios de Yogyakarta definen ambos conceptos y estos, fueron los considerados por las magistradas. La orientación sexual "se refiere a la capacidad de cada persona de sentir una profunda atracción emocional, afectiva y sexual por personas de un género diferente al suyo, o de su mismo género, o de más de un género, así como a la capacidad de mantener relaciones íntimas y sexuales con estas personas" (Principios de Yogyakarta, 2007, p.6). La identidad de género "se refiere a la vivencia interna e individual del género tal como cada persona la siente profundamente, la cual podría corresponder o no con el sexo asignado al momento del nacimiento, incluyendo la vivencia personal del cuerpo (que podría involucrar la modificación de la apariencia o la función corporal a través de medios médicos, quirúrgicos o de otra índole, siempre que la misma sea libremente escogida) y otras expresiones de género, incluyendo la vestimenta, el modo de hablar y los modales" (Principios de Yogyakarta, 2007, p.6). Considerando lo antes expuesto el órgano colegiado decanta por identificar al solicitante como gay y lo define en su resolución, de forma similar a la Corte IDH (2017), como "un hombre que es atraído física, romántica y/o emocionalmente de manera perdurable por otros hombres, aunque el término gay también se puede utilizar para describir tanto hombres gays como mujeres (lesbianas)" (16586/17-17-09-8, 2018, p.18). 


\section{PRINCIPIOS INTERNACIONALES}

El artículo 5 de la ley sobre refugiados, protección complementaria y asilo político señala que, en aplicación de esa ley, inter alia, deberán observarse los siguientes principios y criterios: no devolución; no discriminación; interés superior del niño; unidad familiar; no sanción por ingreso irregular, y confidencialidad. Empero, con base en tres principios relacionados al Derecho Internacional de los Refugiados la Sala resolvió el presente caso: a) No devolución / non-refoulement; b) Igualdad y No Discriminación, y; c) Principios de Yogyakarta (18 y 23).

\section{a. No devolución / non-refoulement: Este} principio "constituye a la vez la piedra angular de la protección internacional de las personas refugiadas o asiladas y de las personas solicitantes de asilo" y "constituye una norma consuetudinaria de Derecho Internacional" (Corte IDH, 2013, párr. 151). Asimismo, la Comisión Interamericana de Derechos Humanos en su Informe sobre la Situación de los Derechos Humanos de los Solicitantes de Asilo en el Marco del Sistema Canadiense de la Determinación de la Condición de Refugiado, señaló:

La prohibición de devolución significa que cualquier persona reconocida como refugiado o que solicita reconocimiento como tal puede acogerse a esta protección para evitar su expulsión. Esto necesariamente implica que esas personas no pueden ser rechazadas en la frontera o expulsadas sin un análisis adecuado e individualizado de sus peticiones. (Comisión
Interamericana de Derechos Humanos [CIDH], 2015, párr. 439)

En el artículo 33 numeral 1 de la Convención de 1951 el principio de no devolución está definido en el sentido que ningún estado parte de la Convención podrá por expulsión o devolución, poner en modo alguno a un refugiado en las fronteras de los territorios donde su vida o su libertad peligre por causa de su raza, religión, nacionalidad, pertenencia a determinado grupo social, o de sus opiniones políticas.

b. Igualdad y No Discriminación: En principio, los Estado tienen la obligación de "abstenerse de realizar acciones que de cualquier manera vayan dirigidas, directa o indirectamente, a crear situaciones de discriminación de jure o de facto" (Corte IDH, 2003, párr. 103) y a "adoptar medidas positivas para revertir o cambiar situaciones discriminatorias existentes en sus sociedades, en perjuicio de determinado grupo de personas" (Corte IDH, 2003, párr. 104). Como mencionó la Sala, para el presente caso, velar por la igualdad y no discriminación "esencialmente relacionada con la orientación sexual e identidad de género" (16586/17-17-098, 2018, p.4). En la Observación General número 18 del Comité de Derechos Humanos -considerado por el órgano colegiado para entender el alcance del término discriminación- se afirma que la [...] no discriminación, junto con la igualdad ante la ley y la igual protección de la ley sin ninguna discriminación constituye un principio básico y general relativo a la protección de los derechos humanos" (Organización de las Naciones Unidas [ONU], 1989, párr. 1) 
y concomitantemente al alcance de la no discriminación, aseveró:

$[\ldots]$ el término "discriminación",
tal como se emplea en el Pacto, debe entenderse referido a toda distinción, exclusión, restricción o preferencia que se basen en determinados motivos, como la raza, el color, el sexo, el idioma, la religión, la opinión política o de otra índole, el origen nacional o social, la posición económica, el nacimiento o cualquier otra condición social, y que tengan por objeto o por resultado anular o menoscabar el reconocimiento, goce o ejercicio, en condiciones de igualdad, de los derechos humanos y libertades fundamentales de todas las personas. (ONU, 1989, párr. 7)

c. Principios 18 y 23 de Yogyakarta: En términos genérales los Principios de Yogyakarta "se ocupan de una amplia gama de normas de derechos humanos y de su aplicación a las cuestiones relativas a la orientación sexual y la identidad de género" y "afirman la obligación primordial que cabe a los Estados en cuanto a la implementación de los derechos humanos" (Principios de Yogyakarta, 2007, p. 7). En específico, el principio 18 se refiere a la no patologización ni medicalización por motivos de la orientación sexual o de la identidad de género de una persona, al señalar que:

Ninguna persona será obligada a someterse a ninguna forma de tratamiento, procedimiento o exámenes médicos o psicológicos, ni a permanecer confinada en un establecimiento médico, por motivo de su orientación sexual o su identidad de género. Con independencia de cualquier clasificación que afirme lo contrario, la orientación sexual y la identidad de género de una persona no constituyen, en sí mismas, trastornos de la salud y no deben ser sometidas a tratamiento o atención médicas, ni suprimidas. (Principios de Yogyakarta, 2007, p. 25)

El principio 23 se refiere al derecho a procurar asilo a una persona que sea perseguida por motivo de su orientación sexual o su identidad de género y la obligación de no enviar a una persona, bajo cualquier forma, a otro Estado, en el que pudiese verse sujeta a temores fundados de sufrir violaciones de derechos humanos por motivo de su orientación sexual o identidad de género, estableciéndolo de esta manera:

En caso de persecución, incluida la relacionada con la orientación sexual o la identidad de género, toda persona tiene derecho a procurar asilo, y a obtenerlo en cualquier país. Un Estado no podrá remover, expulsar o extraditar a una persona a ningún Estado en el que esa persona pudiera verse sujeta a temores fundados de sufrir tortura, persecución o cualquier otra forma de penas o tratos crueles, inhumanos o degradantes en base a la orientación sexual o identidad de género. (Principios de Yogyakarta, 2007, p. 29)

\section{PARTE RESOLUTIVA}

En este apartado desarrollaremos como el órgano colegiado verificó si se cumplían o no, cada uno de los elementos para el reconocimiento de la condición de refugiado del solicitante CNL.

\section{Encontrarse fuera de su país de origen o} residencia habitual: Este elemento no fue analizado a profundidad en la sentencia, pero en los antecedentes del caso se hace alusión que CNL ingresó al territorio mexicano el 13 de diciembre de 2016 y se 
reconoce a su vez, que es de nacionalidad guatemalteca. (16586/17-17-09-8, 2018)

\section{El Temor fundado (Elementos subjetivos} $y$ objetivos): El elemento subjetivo se dio por acreditado considerando que "la experiencia narrada por el solicitante CNL goza del elemento de credibilidad, pues en primer término se advierte que fue expresada de manera coherente y sin contradicciones" (16586/17-17-098, 2018, pp. 48 y 49). -ver síntesis de los hechos en el primer apartado- en consecuencia, se dio por acreditado que el motivo de su solicitud se basa "en el temor que tiene de que sea privado de la vida incluso por su propia familia, aunado a la discriminación de que ha sido y es sujeto en razón de su preferencia sexual al reconocerse como gay." (16586/17-1709-8, 2018, p. 48). Concomitantemente al elemento objetivo, el Tribunal en vista que los hechos narrados por el solicitante se desenvolvieron "dentro de una dinámica social específica, pues dada la preferencia sexual manifestada por el demandante" se identificó que, "se trata de un componente de género y/o pertenencia a un determinado grupo social que constituye uno de los cinco motivos enumerados en el Artículo 1A (2) de la Convención de 1951" (16586/1717-09-8, 2018, p. 50). Por tal motivo se procedió analizar el contexto en el que viven las personas de la comunidad LGBTI en Guatemala utilizando dos documentos: 1) Informe 2016 de la Organización de los Estados Americanos -OEA- sobre la situación de los derechos humanos en Guatemala: Diversidad, desigualdad y exclusión, y; 2) Guatemala en deuda con derechos para la comunidad LGBTI. Artículo publicado por GUATEVISION el 14 de noviembre de 2017.

De la información sustraída de esos documentos la Sala determinó que la situación en Guatemala "se encuentra afectada por una cuestión coyuntural de discriminación dirigida a las personas que manifiestan sus preferencias sexuales que se refleja particularmente en la exclusión y falta de respeto a los derechos humanos de la comunidad LGBTI," (16586/17-17-098,2018 , pp. 59 y 60) y, en la medida que el probable riesgo derivaba de amenazas que provenían de su propia familia, la comunidad y las prácticas de odio -inter alia, violencia, agresiones, crímenes de odio- que ponen en riesgo la vida y que limitan los derechos de la comunidad LGBTI la novena sala señaló "que no pueda considerarse que hubiera una protección efectiva del Estado" (16586/17-17-09-8, 2018, p. 61).

III. Persecución y sujetos activos: En líneas pasadas se dijo que, conforme a la interpretación del artículo 33 de la Convención de 1951, el término "persecución" significa toda amenaza contra la vida o la libertad de una persona; o violaciones graves de los derechos humanos. En esa línea, la Sala Regional Metropolitana del TFJA identifica como sujeto activo de la persecución a agentes no estatales, en específico, "de su propia familia, además de la comunidad más cercana a él, quienes en reiteradas ocasiones y por diversos medios le han manifestado sus intenciones de hacerle daño, refiriendo 
específicamente su intención de privarle de la vida," (16586/17-17-09-8, 2018, pp. 62 y 63). lo que constituye una amenaza contra la vida. Asimismo, considerándose el contexto de violencia, agresiones y limitaciones de los derechos de la comunidad LGBTI en Guatemalaidentificada por la Sala, se cristalizan violaciones a los derechos humanos en vista que en consecuencia del accionar de los persecutores "ubica al afectado en un estado de perturbación psicológica, que impide que se desarrollen de manera plena, y que los mantiene en estado de incertidumbre, sin que pueda asegurarse su bienestar" (16586/17-17-09-8, 2018, p.64).

IV.Motivo de la Convención de 1951, de la Declaración de Cartagena o la ley sobre refugiados, protección complementaria y asilo político: La Sala da por acreditado que la amenaza contra la vida y las violaciones a los derechos humanos en contra del solicitante CNL derivan del hecho de reconocerse como gay, es decir por pertenecer a la comunidad LGBTI, traducida como grupo social. El nexo entre los temores fundados de persecución y el motivo de persecución -pertenecer a un grupo social- cuando se trata de agentes no gubernamentales, se materializa ante la incapacidad del Estado Guatemalteco de proteger al solicitante. El TFJA fundamenta este argumento en las Directrices sobre la protección internacional: "Pertenencia a un determinado grupo social" en el contexto del Artículo 1A (2) de la Convención de 1951 sobre el Estatuto de los Refugiados y/o su Protocolo de 1967, que en su párrafo
21 señala conducentemente lo siguiente:

21.Es normal que un solicitante alegue que una persona que inflige o amenaza con hacer daño está actuando por una de las razones identificadas en la Convención. Por lo tanto, si un agente no gubernamental inflige o amenaza con persecución basado en un motivo de la Convención y el Estado carece de la voluntad o es incapaz de proteger al solicitante, entonces se establece una relación causal. Es decir, la víctima se ve afectada por causa de un motivo de la Convención

Sobre este último punto, se estima conveniente mencionar que en la jurisprudencia de la Corte IDH a partir del caso Velásquez Rodríguez Vs Honduras ha asentado que en función al artículo 1.1 de la Convención Americana de Derechos Humanos, los Estados partes tienen "los deberes fundamentales" de respeto (obligación negativa) y garantía (obligación positiva) (Corte IDH, 1988, párr. 164). De igual manera que "aunque un acto $\mathrm{u}$ omisión de un particular tenga como consecuencia jurídica la violación de determinados derechos humanos de otro particular, aquel no es automáticamente atribuible al Estado," y para determinar si existió un incumplimiento del deber de prevenir -garantía- violaciones a los derechos a la vida y/o integridad personal de un individuo debe verificarse que: i) las autoridades estatales sabían, o debían haber sabido, de la existencia de un riesgo real e inmediato para la vida y/o integridad personal de un individuo o grupo de individuos determinado, y que-; ii) tales autoridades no adoptaron las medidas necesarias dentro del ámbito de sus 
atribuciones que, juzgadas razonablemente, podían esperarse para prevenir o evitar ese riesgo. (Corte IDH, 2015, párr. 109)

V. Alternativa de huida: La Sala del TFJA señaló que, para el reconocimiento de la condición de refugiado al solicitante era necesario considerar esta figura. De acuerdo con esto, se tomó en cuenta las Directrices sobre protección internacional: La "alternativa de huida interna o reubicación" en el contexto del artículo 1A (2) de la Convención de 1951 o el Protocolo de 1967 sobre el Estatuto de los Refugiados. En ese instrumento se indica que la alternativa de huida interna o reubicación se refiere, a la posibilidad de trasladar a la persona a una "zona específica del país donde no haya riesgo de temores fundados de persecución y donde, dadas las circunstancias particulares del caso, es razonable esperar que el individuo pueda asentarse y llevar una vida normal" (ACNUR, 2003, párr.6). Sin embargo, cuando exista el riesgo que el agente no estatal pueda perseguir al solicitante en la zona propuesta, entonces esa zona no puede ser considerada como una alternativa de huida interna o reubicación lo que dependerá de que "si es probable que el agente de persecución busque al solicitante en esa zona, y de si se dispone allá de protección estatal contra el daño temido" (ACNUR, 2003, párr. 7, letra a, romano iii). Aunado a lo anterior, la determinación de si la zona de propuesta es una alternativa apropiada exige una valoración a lo largo del tiempo, es decir, "si la zona propuesta constituye una alternativa significativa hacia el futuro" (ACNUR, 2003, párr. 8).
La Sala del TFJA considerándose las directrices antes mencionadas, las declaraciones del solicitante, como también la información recabada por la Sala respecto a la situación de Guatemala, se concluyó que "la alternativa de huida interna o reubicación no puede suponer una opción viable para el solicitante, pues su vida se encontraría en peligro, además de que se ve limitado e incluso impedido el ejercicio de sus derechos a expresar sus preferencias sexuales" (16586/17-17-09-8, 2018, p. 67). La Sala también señaló que la "intolerancia hacia las personas LGBTI tiende a existir en todo el país de origen del solicitante" (16586/17$17-09-8,2018$, p.67) y que, "no se cuenta con alternativa de huida cuando la reubicación implica el (re) ocultamiento de la orientación sexual y/o identidad de género para estar seguros" (16586/17-17-09-8, 2018, p. 68). Por lo que a una persona no se puede negar la protección internacional "con base en un requisito que cambie u oculte su identidad, opiniones o características con el fin de evitar la persecución. Las personas LGBTI tienen tanto derecho a la libertad de expresión y de asociación como las demás personas" (16586/17-17-09-8, 2018, p.68).

\section{CONCLUSIONES}

Las personas LGBTI en Guatemala, Honduras y El Salvador, viven en un contexto de discriminación por parte de la sociedad y en consecuencia de ello se ven obligados a ocultar su identidad de género o/y orientación sexual e incluso, como en el presente caso, huir de sus países en busca de protección internacional. En este caso en específico, la Novena Sala Regional Metropolitana del 
Tribunal Federal de Justicia Administrativa así lo reconoce al señalar que en Guatemala existe una situación coyuntural -o bien estructural- de discriminación con motivo de la orientación sexual y la identidad de género que se refleja particularmente en la exclusión y falta de respeto a los derechos humanos de la comunidad LGBTI perpetrada por diferentes agentes y además, haciendo una correcta aplicación de control de convencionalidadconstitucionalidad construye una definición de refugiado incluyendo un componente de género de conformidad de la normativa de origen tanto nacional como internacional en materia de refugiados y se pronunció sobre el fondo del asunto analizando los hechos y actos controvertidos del caso desde una perspectiva de derechos humanos y con base a principios relacionados al Derecho Internacional de los Refugiados y sobre la aplicación de la legislación internacional de derechos humanos en relación con la orientación sexual y la identidad de género. Con ello la Sala resuelve tomando una posición progresista y conocedora de estándares y principios internacionales sobre la materia.

Asimismo, en el fallo de fecha 13 marzo de 2018 señaló que el hecho que un solicitante pueda evitar la persecución por ocultar o por ser "discreto" sobre su orientación sexual o identidad de género, o que lo haya hecho anteriormente, no es una razón válida para negar la condición de refugiado y en consecuencia de ello, "a una persona no se le puede negar la condición de refugiado con base en un requisito que cambie u oculte su identidad, opiniones o características con el fin de evitar la persecución". (16586/17-17-
09-8, 2018, p.68) Con esta afirmación se hace una reivindicación de derechos al sostener que las personas LGBTI no deben ocultar sus opiniones, identidad, o características con el fin de evitar la persecución, es por ello que ningún ente encargado de conocer y resolver las solicitudes de reconocimiento de la condición de refugiado -La COMAR en Méxicopueda negar el reconocimiento del Estatuto de Refugiado por ese motivo. Finalmente, la Novena Sala Regional Metropolitana del Tribunal Federal de Justicia Administrativa falló señalando que la parte actora había acreditado su pretensión y declaró la nulidad de la resolución impugnada tras realizar un análisis exhaustivo del caso acreditando la existencia de un temor fundado y que el motivo de la persecución tenía que ver con la pertenencia del solicitante a un "determinado grupo social" en razón de la orientación sexual. El precedente que deja este fallo significa un gran avance en materia de asilo que es digno de destacar, encaminado hacia la senda de la igualdad de género y protección contra violaciones de derechos humanos en contra de personas que pertenecen al grupo LGBTI en México y en nuestra región.

\section{BIBLIOGRAFÍA}

Alto Comisionado de las Naciones Unidas para los Refugiados [ACNUR]. (2003). La "alternativa de huida interna o reubicación" en el contexto del artículo 1 A (2) de la Convención de 1951 o el Protocolo de 1967 sobre el Estatuto de los Refugiados. HCR/GIP/03/04. https://www.acnur.org/ fileadmin/Documentos/BDL/2004/2551. pdf?file $=$ t $3 /$ fileadmin $/$ Documentos $/$ BDL/2004/2551 
Alto Comisionado de las Naciones Unidas para los Refugiados [ACNUR]. (2010). Nota de Orientación Sobre las Solicitudes de la Condición de Refugiado Relacionadas con las Víctimas de Pandillas Organizadas.

Alto Comisionado de las Naciones Unidas para los Refugiados [ACNUR]. (2011a). Manual y Directrices Sobre Procedimientos y Criterios para Determinar la Condición de Refugiado en virtud de la Convención de 1951 y el Protocolo de 1967 sobre el Estatuto de los Refugiados. https://www. acnur.org/5d4b20184.pdf

Alto Comisionado de las Naciones Unidas para los Refugiados [ACNUR]. (2011b). Estados Partes de la Convención de 1951 sobre el Estatuto de los Refugiados y el Protocolo de 1967, al 30 de junio de 2011. http:// www.acnur.org/fileadmin/Documentos/ BDL/2001/0506.pdf?file=fileadmin $/$ Documentos/BDL/2001/0506

Alto Comisionado de las Naciones Unidas para los Refugiados [ACNUR]. (s.f.) Población LGBTI en México y Centroamérica. http:// old.acnur.org/donde-trabaja/america/ mexico/poblacion-lgbti-en-mexico-ycentroamerica/

Amnistía Internacional. (2017). La crisis de personas refugiadas LGBTI de Centroamérica. https://www.amnistia. org/ve/noticias/2017/11/4171/1acrisis-de-personas-refugiadas-lgbti-decentroamerica
Comisión Interamericana de Derechos Humanos [CIDH]. (2015). Movilidad humana estándares interamericanos, OEA/ Ser. L /V/II.Doc. 46/15.

Corcuera Cabezut, S. (2016). Los derechos humanos, aspectos jurídicos generales. Oxford.

Expediente 16586/17-17-09-8, (2018, 13 de marzo). Novena Sala Regional Metropolitana. CNL Vs Delegación en Veracruz de la COMAR. (Rodríguez Pavón, E).

Familia Pacheco Tineo Vs. Estado Plurinacional de Bolivia (Excepciones Preliminares, Fondo, Reparaciones y Costas). (2013, 25 de noviembre). Corte Interamericana de Derechos Humanos [Corte IDH].

Ley sobre refugiados, protección complementaria y asilo político [LRPCAP]. (2011, 27 de enero). Cámara de diputados del congreso de la unión. http://www. diputados.gob.mx/LeyesBiblio/pdf/ LRPCAP 301014.pdf

Opinión Consultiva OC-18/03, (2003, 17 de septiembre). Corte Interamericana de Derechos Humanos [Corte IDH]. Condición jurídica y derechos de los migrantes indocumentados. Solicitada por los Estados Unidos Mexicanos.

Opinión Consultiva. OC-24/17 (2017, 24 de noviembre). Corte Interamericana de Derechos Humanos [Corte IDH]. Identidad 
de género, e igualdad y no discriminación a parejas del mismo sexo, solicitada por la República de Costa Rica.

Organización de las Naciones Unidas [ONU], Comité de Derechos Humanos. (1989, 10 de noviembre). Observación General 18: No discriminación. http://www.acnur. org/t3/fileadmin/scripts/doc.php?file=t3/ fileadmin/Documentos/BDL/2001/1404

Principios de Yogyakarta, Principios sobre la aplicación de la legislación internacional de derechos humanos en relación con la orientación sexual y la identidad de género (2007, marzo). http://www.refworld.org/ cgi-bin/texis/vtx/rwmain/opendocpdf. pdf?reldoc $=\mathrm{y} \&$ docid $=48244 \mathrm{e} 9 \mathrm{f} 2$

Sánchez Zorrilla, M. (2011). La metodología en la investigación jurídica: características peculiares y pautas generales para investigar en el derecho. Revista Telemática de Filosofía del Derecho, 14(1), 317-358.

Velásquez Paiz y Otros Vs. Guatemala (excepciones preliminares, fondo, reparaciones y costas). (2015, 19 de noviembre). Corte Interamericana de Derechos Humanos [Corte IDH].

Velásquez Rodríguez Vs. Honduras (Fondo). (1988, 29 de julio). Corte Interamericana de Derechos Humanos [Corte IDH].

Yatama Vs. Nicaragua (Excepciones Preliminares, Fondo, Reparaciones y Costas). (2005, 23 de junio). Corte Interamericana de Derechos Humanos [Corte IDH]. 